\title{
THE ASSOCIATION OF LEFT VENTRICULAR HYPERTROPHY WITH INTRAVENTRICULAR DYSSYNCHRONY AT REST AND DURING EXERCISE IN HYPERTENSIVE PATIENTS
}

\author{
Hye-Sun SeO, MD, PHD ${ }^{1}$, Youn-HAENG CHO, MD, PHD ${ }^{1}$, JAE HuK CHOI, MD ${ }^{1}$, \\ Jon SUH, MD, PHD ${ }^{1}$, NAE-HEE LEE, MD, PHD ${ }^{1}$ AND OH KYUNG LIM, MD, PHD ${ }^{2}$ \\ 'DIVISION OF CARDIOLOGY, DEPARTMENT OF INTERNAL MEDICINE, SOONCHUNHYANG UNIVERSITY HOSPITAL, BUCHEON, KOREA \\ ${ }^{2}$ DEPARTMENT OF REHABILITATION MEDICINE, GACHON UNIVERSITY GIL HOSPITAL, INCHEON, KOREA
}

BACKGROUND: Impaired exercise tolerance with dyspnea is common in hypertensive patients and this may be due to the exaggeration of nonuniform ventricular activation during exercise. So we want to evaluate the effect of left ventricular hypertrophy (LVH) on systolic intraventricular dyssynchrony during exercise.

METHODS: A total of 85 patients with hypertension who having exertional dyspnea and 30 control individuals were enrolled. Exercise stress echocardiography was performed using a symptom limited, multistage supine bicycle test. To evaluate the dyssynchrony of left ventricular (LV), we calculated the standard deviation (SD) of the averaged time-to-peak systolic velocity (TPs-SD, ms) of 12 middle and basal LV segments obtained from the three standard apical views at rest and peak exercise.

RESULTS: There was no significant difference in systolic blood pressure (BP) and heart rate between the two groups. TPs-SD was significantly higher in patients with LVH at rest $(31.5 \pm 12.1$ vs. $22.0 \pm 12.6 \mathrm{~ms}, p=0.002)$ with exaggeration of the degree at peak exercise $(39.0 \pm 11.9$ vs. $24.6 \pm 13.3 \mathrm{~ms}, p<0.001)$. Multiple regression analysis showed LV mass index was independently associated with LV dyssynchrony at peak exercise $(\beta=0.515, p=0.001)$ when controlled for age, sex, and systolic $\mathrm{BP}$ at peak exercise.

CONCLUSION: Intraventricular systolic dyssynchrony during exercise is significantly associated with the degree of LVH in hypertensive patients.

KEY WORDS: Left ventricular hypertrophy · Intraventricular dyssynchrony $\cdot$ Hypertension.

\section{INTRODUCTION}

Left ventricular hypertrophy (LVH) in hypertension is the response to increased afterload, and is associated with left ventricular (LV) relaxation abnormalities. ${ }^{1)}$ Even in the normal LV systolic performance, hypertrophy results in a rise in left atrial (LA) pressure and pulmonary edema at loading condition. Dyspnea is very common symptom in these patients especially during exercise. ${ }^{2)}$

Myocardial hypertrophy, that is increased interstitial fibrosis, has been known to be the morphological change that causes diastolic myocardial stiffness. ${ }^{3-6)}$ Myocardial disarray typically shown in hypertrophic cardiomyopathy (HCM) also affects the ventricular relaxation.

It is well known that the distribution and magnitude of LVH are not uniform in patients with HCM, which results in regional heterogeneity of LV systolic and diastolic function. ${ }^{7-10)}$ This temporal and spatial nonuniformity is also an important determinant of global LV function in coronary and hypertensive heart disease. ${ }^{11)}$ Actually, De Marchi et al. ${ }^{12)}$ showed asymmetrical distribution of $\mathrm{LVH}$ is related to regional asynchrony of $\mathrm{LV}$ relaxation in hypertensive heart disease. However, until now, the regional asynchrony and nonuniform distribution of hyper-

- Received: October 2, 2012 •Revised: December 17, 2012 •Accepted: December 17, 2012

- Address for Correspondence: Hye-Sun Seo, Division of Cardiology, Department of Internal Medicine, Soonchunhyang University Hospital, 170 Jomaru-ro,

Wonmi-gu, Bucheon 420-767, Korea Tel: +82-32-621-5138, Fax: +82-32-621-6461, E-mail: haesunfree@hotmail.com

- This is an Open Access article distributed under the terms of the Creative Commons Attribution Non-Commercial License (http://creativecommons.org/licenses/by-nc/3.0)

which permits unrestricted non-commercial use, distribution, and reproduction in any medium, provided the original work is properly cited. 
trophied myocardium has been evaluated only at resting state although this dyssynchrony maybe exaggerated during exercise. And this can be the cause of exertional dyspnea in patients with $\mathrm{LVH}$ due to lack of uniform contraction of myocardium, relative decrease in stroke volume and diastolic asynchrony.

Therefore, in this study, we investigated the degree of myocardial dyssynchrony of hypertrophied myocardium and the relationship between distribution of myocardium and regional dyssynchrony during exercise as well as at rest.

\section{METHODS}

\section{PATIENTS}

We selected 85 patients who relatively well controlled, treated hypertension and complained of exertional dyspnea and 30 control individuals after receiving informed consent. Among the eighty five patients, 30 patients had LVH. The patients with any of the following were excluded from participation: valvular heart disease; peripheral vascular disease; significant systemic disease; history of inflammatory disease; symptomatic cerebrovascular disease (including previous transient ischemic attack within 6 months); history of significant coronary artery disease; a clinically significant atrioventricular conduction disturbance; history of atrial fibrillation or other serious arrhythmia; history of congestive heart failure; liver cirrhosis; severe hypertension (> 180/110 $\mathrm{mmHg}$ ); serum creatinine > $1.4 \mathrm{mg} / \mathrm{dL}$; pregnant women.

\section{TWO-DIMENSIONAL AND DOPPLER ECHOCARDIOGRAPHY}

Echocardiography was performed with an ultrasound system (Vivid 7 GE Vingmed, Horten, Norway) with a 2.5$\mathrm{MHz}$ transducer. Standard 2-dimensional (2D) measurements [end-diastolic and end-systolic dimensions, ventricular septum and posterior wall thickness, LA volume index, LV mass index (LVMI), LV outflow tract] including LV ejection fraction were measured with the patient in the left lateral position. LV mass (LVM) was calculated using the Devereux-mod- ified American Society of Echocardiography cube formula, ${ }^{13)}$ and LVMI was obtained by dividing the LVM by the body surface area. LVH was considered present when LVMI was greater than $105 \mathrm{~g} / \mathrm{m}^{2}$ in men or $95 \mathrm{~g} / \mathrm{m}^{2}$ in women. ${ }^{13)}$ A 1- to 2-mm pulsed Doppler sample volume was placed at the mitral valve tip, and mitral flow velocities from 5 to 10 cardiac cycles were recorded. The following variables were obtained: peak velocity of early filling (E) and late (A) filling, deceleration time (DT) of the $\mathrm{E}$ wave velocity and ratio of $\mathrm{E}$ over $\mathrm{A}$.

Doppler with the sample volume at the tip of the mitral valve leaflets, systolic (S') and early (E') and late (A') diastolic mitral annular velocities were measured in the apical 4-chamber view using pulsed wave Doppler tissue imaging by spectral pulsed Doppler signal filters, bypassing highpass filter, adjusting Nyquist limit until $15-20 \mathrm{~cm} / \mathrm{sec}$ (close to myocardial velocities), and using the minimal optimal gain.

After the standard echocardiographic examination, Doppler tissue imaging for offline color tissue velocity imaging was again activated in the apical 4 chamber, 5 chamber (not shown) and 2 chamber image (Fig. 1). ${ }^{14)}$

\section{EXERCISE STRESS ECHOCARDIOGRAPHY}

Exercise stress echocardiography was performed using a symptom limited, multistage supine bicycle exercise test with a variable load bicycle ergometer (Medical Positioning Inc., Kansas City, MO, USA). The patients pedaled at constant speed beginning at a workload of $25 \mathrm{~W}$, with an incremental workload of $25 \mathrm{~W}$ every 3 minutes. During exercise, the standard 2D measurements including LV ejection fraction, mitral inflow velocities (E, A, DT, E/A) and tissue Doppler parameters (S', E', A') were measured and measurements was recorded with simultaneous electrocardiography at a sweep speed of 50 to $100 \mathrm{~mm} / \mathrm{s}^{15)}$ Each measurement was made at baseline, at each stage of exercise, and during recovery. To evaluate the intra- and interpersonal measurement variabilities, the measurements were performed off-line by 2 investigators who were blinded to the status of patients in randomly selected $20 \mathrm{pa}-$ tients. Patients who demonstrated evidence of overt myocar-
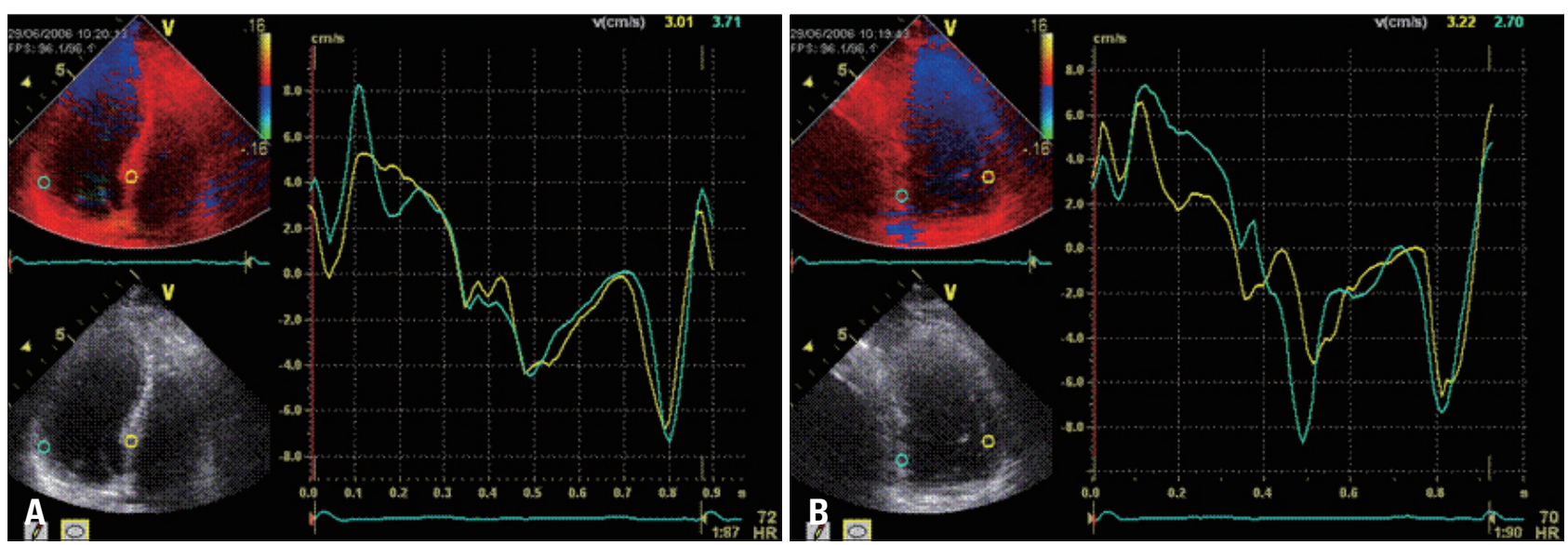

Fig. 1. Doppler tissue imaging for offline color tissue velocity imaging in the apical 4 chamber (A), and 2 chamber (B) image. 
dial ischemia during exercise, such as significant ST segment change or development of regional wall motion abnormality, were excluded from analysis.

By use of Doppler tissue imaging, the following regional parameters were evaluated in 12 different basal, medial myocardial segments: systolic (S'), early- and late-diastolic (E' and
$\left.A^{\prime}\right)$, peak velocities and regional isovolumetric contraction time (ms). Time from the $\mathrm{Q}$ wave on the electrocardiogram to the peak velocity of regional myocardium was measured at each 12 segments. Systolic dyssynchrony index was defined as standard deviation (SD) of time from $\mathrm{Q}$ wave to peak systolic velocity of 12 segments (TPs) and diastolic dyssynchrony index

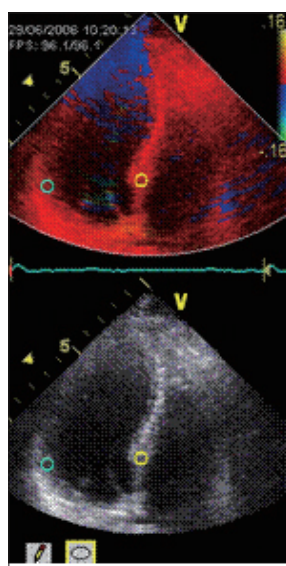

A

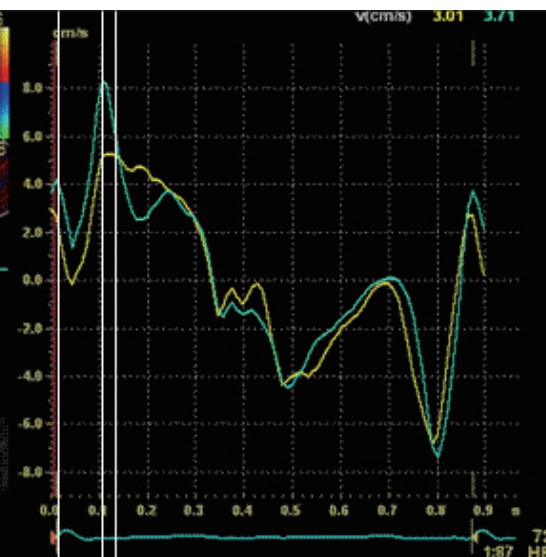

$\longleftrightarrow$ ↔

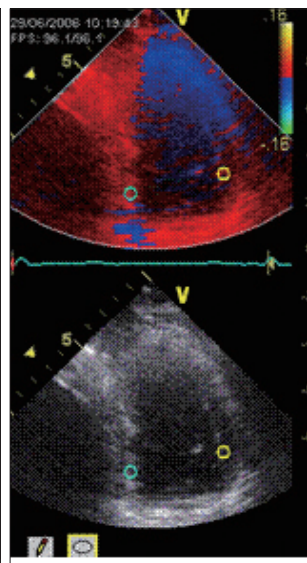

B

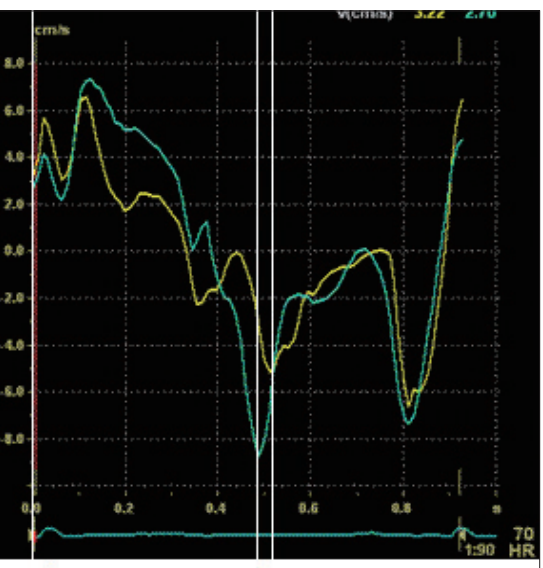

$\longleftrightarrow$

Fig. 2. The process to define systolic and diastolic dyssynchrony. A: Systolic dyssynchrony: The difference of time from the $Q$ wave on the electrocardiogram to the peak velocity of two basal myocardium. B: Diastolic dyssynchrony: The difference of time from $Q$ wave to myocardial early diastolic velocity between anterior and inferior basal myocardium.
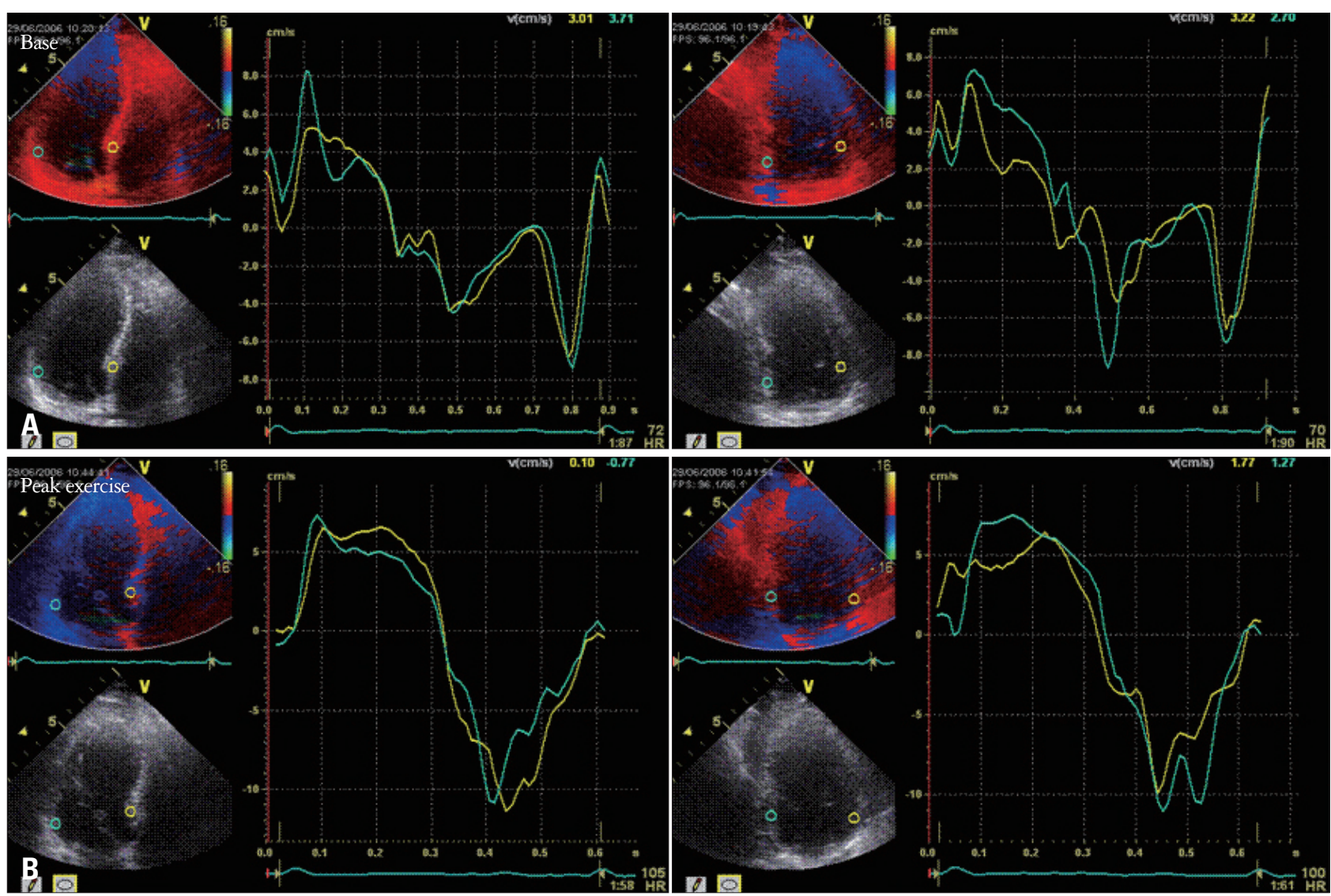

Fig. 3. Upper panel, tissue velocity imaging at resting state; (A) 4 chamber view; (B) 2 chamber view. At exercise, modified standard deviation (SD) was applied. SD/heart rate was applied considering heart rate. 
was defined as $\mathrm{SD}$ of the time from $\mathrm{Q}$ wave to myocardial early diastolic velocity (TPe) measured (Fig. 2). ${ }^{14)}$ And at exercise, modified SD (SD / heart rate) was applied considering heart rate (Fig. 3). ${ }^{15)}$

\section{STATISTICAL ANALYSIS}

Values were expressed as mean $\pm \mathrm{SD}$. Comparison of the dichotomous variables was performed using the chi-square analysis. Comparison of continuous variables between the two study groups was performed using the student's t-test. Values of $p<0.05$ was considered statistically significant. Statistical analysis was performed with SPSS 11.0 statistical program (SPSS Inc., Chicago, IL, USA).

\section{RESULTS}

\section{CLINICAL CHARACTERISTICS AND BASELINE ECHOCARDIOGRAPHIC DATA}

The age of patients having $\mathrm{LVH}$ is older than patients without LVH (Table 1). Reasonably LV dimension at diastolic phase, LV mass and LA volume was larger in LVH group. However, there was no difference in ejection fraction between two groups.

\section{HEMODYNAMIC PARAMETERS AT REST AND DURING EXERCISE}

Hemodynamic parameters at rest and during exercise were shown in Table 2. Baseline and during peak exercise, there was no significant difference in blood pressure (BP), heart rate (HR) and ejection fraction between two groups of hypertensive patients and their antihypertensive medications prescribed were similar without significant difference. However, the exercise duration is shorter in $\mathrm{LVH}$ group than no-LVH group. The main cause of stopping of exercise was that they complained of difficulty in breathing.

We measured many parameters as described at methods and E over E' (E/E') is considered as representative of LA pressure. $S$ prime (S') is the contractile function of myocardium at each stage (Table 3).

\section{SYSTOLIC, DIASTOLIC PARAMETERS AT REST AND DURING EXERCISE IN LVH AND NON-LVH GROUP}

As you can see in Table 3, at $50 \mathrm{~W}, \mathrm{E} / \mathrm{E}$ ' value is significantly higher in LVH group which means diastolic dysfunction is worse at exercise in LVH group on the contrary similar E/E' at resting state in two groups. Over than $50 \mathrm{~W}$, it is more difficult

Table 1. Characteristics of patients with and without LVH

\begin{tabular}{|c|c|c|c|c|}
\hline & Control $(\mathrm{n}=30)$ & No LVH $(\mathrm{n}=55)$ & $\operatorname{LVH}(\mathrm{n}=30)$ & $p$-value \\
\hline Age (yr) & $52.4 \pm 9.3$ & $53.3 \pm 11.8$ & $58.7 \pm 9.4$ & 0.033 \\
\hline Gender $(\mathrm{M}: \mathrm{F})$ & $26: 29$ & $26: 29$ & $14: 16$ & 0.222 \\
\hline BMI $\left(\mathrm{kg} / \mathrm{m}^{2}\right)$ & $23.4 \pm 3.2$ & $24.6 \pm 2.8$ & $24.1 \pm 2.7$ & 0.594 \\
\hline $\operatorname{LVEDD}(\mathrm{mm})$ & $45.5 \pm 4.7$ & $48.5 \pm 3.8$ & $50.7 \pm 3.8$ & 0.016 \\
\hline $\operatorname{LVESD}(\mathrm{mm})$ & $30.0 \pm 2.8$ & $31.5 \pm 3.4$ & $32.3 \pm 3.6$ & 0.328 \\
\hline LV mass (g) & $139 \pm 28$ & $158 \pm 32$ & $209 \pm 54$ & $<0.001$ \\
\hline $\operatorname{LVMI}(\mathrm{g} / \mathrm{BSA})$ & $84 \pm 15$ & $93 \pm 15$ & $129 \pm 17$ & $<0.001$ \\
\hline $\mathrm{EF}(\%)$ & $65 \pm 5.2$ & $68 \pm 5$ & $70 \pm 7$ & 0.377 \\
\hline LA volume index $(\mathrm{mL})$ & $24.5 \pm 6.4$ & $26.3 \pm 10.2$ & $31.1 \pm 9.6$ & 0.047 \\
\hline
\end{tabular}

LVH: left ventricular hypertrophy, M: male, F: female, BMI: body mass index, LVEDD: left ventricular end diastolic dimension, LVESD: left ventricular end systolic dimension, LVMI: left ventricular mass index, BSA: body surface area, EF: ejection fraction, LA: left atrium

Table 2. Hemodynamic parameters at rest and during exercise and prescribed drugs

\begin{tabular}{|c|c|c|c|}
\hline & $\mathrm{LVH}(\mathrm{n}=30)$ & No LVH $(\mathrm{n}=55)$ & $p$-value \\
\hline Base HR (bpm) & $60 \pm 9$ & $64 \pm 9$ & 0.094 \\
\hline Peak HR (bpm) & $115 \pm 18$ & $121 \pm 21$ & 0.234 \\
\hline Base SBP (mmHg) & $140 \pm 22$ & $134 \pm 15$ & 0.165 \\
\hline Peak SBP (mmHg) & $182 \pm 28$ & $184 \pm 25$ & 0.790 \\
\hline Peak EF (\%) & $69.5 \pm 5.4$ & $71.2 \pm 6.6$ & 0.598 \\
\hline Exercise duration (sec) & $496 \pm 265$ & $521 \pm 195$ & $0.016 *$ \\
\hline Diuretics (\%) & 21.5 & 19.6 & 0.447 \\
\hline Beta blockers (\%) & 30.4 & 28.6 & 0.847 \\
\hline $\mathrm{CCB}(\%)$ & 24.5 & 21.3 & 0.978 \\
\hline ACEi or ARB (\%) & 40.2 & 39.8 & 0.667 \\
\hline
\end{tabular}

* Means that there was significant difference in exercise duration between two groups. LVH: left ventricular hypertrophy, HR: heart rate, SBP: systolic blood pressure, EF: ejection fraction, CCB: Calcium Channel Blocker, ACEi: angiotensin converting enzyme inhibitor, ARB: antiotensin receptor blocker 
Table 3. Systolic, diastolic parameters at rest and during exercise in both groups

\begin{tabular}{lcccc}
\hline & Control $(\mathrm{n}=30)$ & No LVH $(\mathrm{n}=55)$ & LVH $(\mathrm{n}=30)$ & $p$-value \\
\hline E/E' at baseline & $9.5 \pm 2.9$ & $10.8 \pm 3.4$ & $12.2 \pm 3.2$ & 0.082 \\
E/E' at $25 \mathrm{~W}$ & $10.0 \pm 2.7$ & $11.2 \pm 3.7$ & $12.7 \pm 3.5$ & 0.092 \\
E/E' at $50 \mathrm{~W}$ & $10.4 \pm 2.1$ & $11.1 \pm 3.1^{*}$ & $13.5 \pm 3.8$ & 0.009 \\
Delta E/E' & $0.9 \pm 1.4$ & $0.7 \pm 2.6$ & $1.7 \pm 2.6$ & 0.132 \\
S' $^{\prime}$ at baseline & $6.5 \pm 2.4$ & $6.3 \pm 1.0$ & $6.5 \pm 1.4$ & 0.455 \\
S' $^{\prime}$ at $25 \mathrm{~W}(\mathrm{~cm} / \mathrm{s})$ & $7.3 \pm 2.6$ & $7.7 \pm 1.5$ & $7.3 \pm 1.7$ & 0.288 \\
S' $^{\prime}$ at $50 \mathrm{~W}(\mathrm{~cm} / \mathrm{s})$ & $9.6 \pm 3.0$ & $8.6 \pm 1.6$ & $8.1 \pm 1.8$ & 0.194 \\
Peak S' $(\mathrm{cm} / \mathrm{s})$ & $11.7 \pm 2.5$ & $9.4 \pm 2.4$ & $9.0 \pm 2.9$ & 0.537 \\
Delta $S^{\prime}(\mathrm{cm} / \mathrm{s})$ & $4.2 \pm 2.0$ & $3.0 \pm 2.2 *$ & $2.1 \pm 1.8$ & 0.040 \\
\hline
\end{tabular}

*Means significant difference between No LVH group and LVH group. LVH: left ventricular hypertrophy, E: early diastolic mitral inflow velocity, E': early diastolic longitudinal tissue velocity, $S^{\prime}$ : early systolic longitudinal tissue velocity, Delta $S^{\prime}$ : the change of S' from baseline to peak exercise (i.e. contractile reserve)

Table 4. Left ventricular systolic asynchrony at rest and during exercise

\begin{tabular}{lccr}
\hline & LVH $(\mathrm{n}=30)$ & No LVH $(\mathrm{n}=55)$ & $p$-value \\
\hline TPs at rest & $31.5 \pm 12.1$ & $22.0 \pm 12.6$ & 0.002 \\
TPs_SD at rest & $32.1 \pm 13.0$ & $23.3 \pm 13.0$ & 0.005 \\
TPs_SD at peak exercise & $39.0 \pm 11.9$ & $24.6 \pm 13.3$ & $<0.001$ \\
Modified TPs_SD at peak exercise & $74.0 \pm 21.8$ & $48.0 \pm 22.5$ & $<0.001$ \\
Delta SD & $6.9 \pm 16.6$ & $2.1 \pm 15.6$ & 0.233 \\
Modified deltaSD & $42.8 \pm 20.0$ & $24.6 \pm 23.4$ & 0.003 \\
\hline
\end{tabular}

LVH: left ventricular hypertrophy, TPs: the time from Q wave to peak systolic velocity of 12 segments, SD: standard deviation, TPs_SD: TPs_SD/heart rate at peak exercise

Table 5. Left ventricular diastolic asynchrony at rest and during exercise

\begin{tabular}{lccr}
\hline & LVH $(\mathrm{n}=30)$ & No LVH $(\mathrm{n}=55)$ & $p$-value \\
\hline TPe at rest & $75 \pm 12.1$ & $63 \pm 12.6$ & 0.002 \\
TPe_SD at rest & $27 \pm 11.0$ & $18.7 \pm 7.4$ & 0.005 \\
TPe_SD at peak exercise & $42.0 \pm 10.6$ & $30.6 \pm 12.4$ & $<0.001$ \\
Modified TPe_SD at peak exercise & $80.0 \pm 17.6$ & $49.0 \pm 21.3$ & $<0.001$ \\
Delta SD & $15.1 \pm 8.6$ & $11.9 \pm 7.0$ & 0.033 \\
Modified delta SD & $31.5 \pm 10.0$ & $16.6 \pm 23.4$ & 0.003 \\
\hline
\end{tabular}

LVH: left ventricular hypertrophy, TPe: the time from Q wave to peak diastolic velocity of 12 segments, SD: standard deviation, TPe_SD: TPe_SD/heart rate at peak exercise

to measure $\mathrm{E} / \mathrm{E}$ ' value because $\mathrm{E}$ wave is summated with $\mathrm{A}$ wave. Contractile function at $50 \mathrm{~W}$ was similar in two groups, however delta S' (the change from baseline to peak exercise) was definitely lower in LVH group. Therefore, we can suggest that in spite of having similar systolic, diastolic function at resting state, with the exercise, the filling pressure of LV increased much more in LVH group and as well the myocardial contractile function was less increased in LVH group.

\section{SYSTOLIC ASYNCHRONY AT REST AND DURING EXERCISE}

However, in terms of LV asynchrony, there were many differences between two groups. TPs, TPs-SD is shorter in no LVH group even in resting state. This difference was exaggerated at peak exercise. As you can see in Table 4, modified TPs-SD at peak exercise (TPs-SD at peak exercise/HR at peak exercise) was much more increased in LVH group than non-LVH group.

\section{DIASTOLIC ASYNCHRONY AT REST AND DURING EXERCISE}

LV diastolic asynchrony had similar pattern with LV systolic asynchrony. TPe and the SD of 12 segments TPe was shorter in no $\mathrm{LVH}$ group even in resting state. This difference was exaggerated at peak exercise. As you can see in Table 5, modified TPe-SD at peak exercise (the calculated value considering HR) was much more increased in LVH group than non-LVH group.

Multiple regression analysis showed that LVMI was independently associated with LV dyssynchrony at peak exercise $(\beta$ $=0.515, p=0.001$ ) when controlled for age, sex, and systolic $\mathrm{BP}$ at peak exercise (Table 6). 
Intraventricular Dyssynchrony at Exercise in LVH | Hye-Sun Seo, et al.

\section{DISCUSSION}

The principal finding of the present study was that the patients with LVH had systolic and diastolic dyssynchrony at rest and this phenomenon exaggerated with exercise which can explain the dyspnea on exertion in the patients with LVH.

The development of LV dyssynchrony may occur because of electrical conduction delay, myocardial ischemia, or abnormal loading conditions. ${ }^{16) 17)}$

We found that in most segments, LV systolic synchronicity was impaired in hypertensive patients when compared with controls and the impairment was more serious in hypertensive patients with LVH. Diastolic asynchrony was also evident in LVH patients when compared with isolated hypertensive patients, which can be reflected by prolonged TPe in most LV segments and prolonged TPe-max. Kwon et al. ${ }^{18)}$ found similar results of ours. In that study, systolic synchrony was impaired in patients with non-LVH to a similar degree in the LVH group. ${ }^{1819)}$ However, our findings have more important implications. Although the degree of dyssynchrony was impaired similarly in nonLVH group and LVH group at resting state, exercise differentiated these two conditions. As shown in Table 3 and 4, systolic and diastolic dyssynchrony was exaggerated more in LVH group compared to non-LVH group.

Dyssynchrony has emerged as important mechanisms contributing to the progression of heart failure and LV remodeling. ${ }^{20)}$ However, systolic dyssynchrony considered our results, it suggests that hypertension impairs LV function not only by influencing myocardial function, but also by impairing LV synchronicity.

And one of the principal findings in this study is the different response to exercise between male and female. Although we didn't show the subanalysis according to gender, E/E' at 50 $\mathrm{W}$ of exercise was much more elevated in women compared to men $(14.2 \pm 3.1$ vs. $12.8 \pm 2.8, p$ value $=0.024)$. And diastolic dyssynchrony index was also more elevated in women than men (TPe_SD at peak exercise: $41.3 \pm 10.7$ in women vs. $36.0 \pm 9.1$ in men, $p$ value $=0.003)$.

In summary, women are vulnerable to increase in LA pressure and diastolic dyssynchrony especially at exercise. This result can explain the difference in symptoms and short exercise duration. And this phenomenon is similar to previous results. Masoudi et al. ${ }^{21)}$ mentioned differences of women with heart failure as compared to men. They explained the reason was women live longer than men, more frequency of coronary artery disease, diabetes mellitus, depression, and etc. ${ }^{21-23)}$ If we suggest the mechanism in addition to previous causes, diastolic dyssynchrony can be the cause of different women heart failure.

In conclusion, intraventricular systolic dyssynchrony during exercise is significantly associated with the degree of LVH in hypertensive patients and this could be the cause of dyspnea on exertion. And the difference of response according to gender should be more investigated.

\begin{tabular}{|c|c|c|}
\hline & Beta & $p$-value \\
\hline Age & 0.230 & 0.046 \\
\hline $\operatorname{LVMI}\left(\mathrm{mm}^{3}\right)$ & 0.515 & 0.001 \\
\hline Female & 0.304 & 0.023 \\
\hline Peak HR (bpm) & 0.307 & 0.065 \\
\hline Peak BP (mmHg) & 0.114 & 0.529 \\
\hline
\end{tabular}

LVMI: left ventricular mass index, HR: heart rate, BP: blood pressure

\section{LIMITATION}

We used the index of 50 watts of exercise, because as we discussed in discussion, if the extent of exercise is over 50 watts, most of $\mathrm{E}$ wave and $\mathrm{A}$ wave are summated in which condition it is difficult to know the exact value of diastolic parameters. In fact, 50 watt exercise is not peak exercise and the value of peak exercise may be different from that of 50 watts. However, we observed the significant different value of dyssynchrony index and many Doppler indexes between non-LVH group and $\mathrm{LVH}$ group although 50 watt exercise is suboptimal exercise. Therefore we believe that the many indexes and Doppler parameters in the real peak exercise have similar pattern with more exaggerated value.

\section{REFERENCES}

1. Grossman W, Jones D, McLaurin LP. Wall stress and patterns of hypertrophy in the human left ventricle. J Clin Invest 1975;56:56-64.

2. Goodwin JF. Congestive and hypertrophic cardiomyopathies. A decade of study. Lancet 1970;1:732-9.

3. Yelamarty RV, Moore RL, Yu FT, Elensky M, Semanchick AM, Cheung JY. Relaxation abnormalities in single cardiac myocytes from renovascular hypertensive rats. Am J Physiol 1992;262(4 Pt 1):C980-90.

4. Hess OM, Schneider J, Koch R, Bamert C, Grimm J, Krayenbuehl HP. Diastolic function and myocardial structure in patients with myocardial hypertrophy. Special reference to normalized viscoelastic data. Circulation 1981;63:360-71.

5. Shapiro LM, McKenna WJ. Left ventricular hypertrophy. Relation of structure to diastolic function in hypertension. Br Heart J 1984;51:637-42.

6. Douglas PS, Tallant B. Hypertrophy, fibrosis and diastolic dysfunction in early canine experimental hypertension. J Am Coll Cardiol 1991;17:530-6.

7. D’Andrea A, Caso P, Severino S, Scotto di Uccio F, Vigorito F, Ascione L, Scherillo M, Calabrò R. Association between intraventricular myocardial systolic dyssynchrony and ventricular arrbythmias in patients with hypertrophic cardiomyopathy. Echocardiography 2005;22:571-8.

8. Mishiro Y, Oki T, Iuchi A, Tabata T, Yamada H, Abe M, Onose Y, Ito S, Nishitani H, Harada M, Taoka Y. Regional left ventricular myocardial contraction abnormalities and asynchrony in patients with hypertrophic cardiomyopathy evaluated by magnetic resonance spatial modulation of magnetization myocardial tagging. Jpn Circ J 1999;63:442-6.

9. Gillebert TC, Lew WY. Nonuniformity and volume loading independently influence isovolumic relaxation rates. Am J Physiol 1989;257(6 Pt 2):H1927-35.

10. Cardim N, Oliveira AG, Longo S, Ferreira T, Pereira A, Reis RP, Correia JM. Doppler tissue imaging: regional myocardial function in bypertrophic cardiomyopathy and in athlete's heart. J Am Soc Echocardiogr 2003;16:223-32. 
11. Abe H, Tomotsune K. Asynchronous relaxation of the ischemic left ventricle. Jpn Circ J 1982;46:103-12.

12. De Marchi SF, Allemann Y, Seiler C. Relaxation in hypertrophic cardiomyopathy and hypertensive heart disease: relations between hypertrophy and diastolic function. Heart 2000;83:678-84.

13. Lang RM, Bierig M, Devereux RB, Flachskampf FA, Foster E, Pellikka PA, Picard MH, Roman MJ, Seward J, Shanewise JS, Solomon SD, Spencer KT, Sutton MS, Stewart WJ; Chamber Quantification Writing Group; American Society of Echocardiography's Guidelines and Standards Committee; European Association of Echocardiography. Recommendations for chamber quantification: a report from the American Society of Echocardiography's Guidelines and Standards Committee and the Chamber Quantification Writing Group, developed in conjunction with the European Association of Echocardiography, a branch of the European Society of Cardiology. J Am Soc Echocardiogr 2005;18:1440-63.

14. Sohn DW, Chai IH, Lee DJ, Kim HC, Kim HS, Oh BH, Lee MM, Park YB, Choi YS, Seo JD, Lee YW. Assessment of mitral annulus velocity by Doppler tissue imaging in the evaluation of left ventricular diastolic function. J Am Coll Cardiol 1997;30:474-80.

15. Chang SA, Kim HK, Kim DH, Kim YJ, Sohn DW, Oh BH, Park $\mathrm{YB}$. Left ventricular systolic and diastolic dyssynchrony in asymptomatic bypertensive patients. J Am Soc Echocardiogr 2009;22:337-42.

16. Tan HW, Zheng GL, Li L, Wang ZH, Gong HP, Zhang Y, Zhong $\mathrm{M}$, Zhang W. Impaired left ventricular synchronicity in bypertensive pa- tients with ventricular hypertrophy. J Hypertens 2008;26:553-9.

17. Ha TH, Seo HS, Choo WJ, Choi J, Suh J, Cho YH, Lee NH. The Effect of Metabolic Syndrome on Myocardial Contractile Reserve during Exercise in Non-Diabetic Hypertensive Subjects. J Cardiovasc Ultrasound 2011;19:176-82.

18. Kwon BJ, Choi KY, Kim DB, Jang SW, Cho EJ, Youn HJ, Kim JH. Systolic synchrony is impaired in nonleft ventricular hypertrophy of never-treated bypertensive patients. J Hypertens 2011;29:2246-54.

19. Nagueh SF. Mechanical dyssynchrony in congestive heart failure: diagnostic and therapeutic implications. J Am Coll Cardiol 2008;51:18-22.

20. Yuda S, Short L, Leano R, Marwick TH. Myocardial abnormalities in bypertensive patients with normal and abnormal left ventricular filling: a study of ultrasound tissue characterization and strain. Clin Sci (Lond) 2002;103:283-93.

21. Masoudi FA, Havranek EP, Smith G, Fish RH, Steiner JF, Ordin DL, Krumholz HM. Gender, age, and heart failure with preserved left ventricular systolic function. J Am Coll Cardiol 2003;41:217-23.

22. Lund LH, Mancini D. Heart failure in women. Med Clin North Am 2004;88:1321-45, xii.

23. Gottlieb SS, Khatta M, Friedmann E, Einbinder L, Katzen S, Baker B, Marshall J, Minshall S, Robinson S, Fisher ML, Potenza M, Sigler B, Baldwin C, Thomas SA. The influence of age, gender, and race on the prevalence of depression in heart failure patients. $J$ Am Coll Cardiol 2004;43:1542-9. 